Historic, archived document

Do not assume content reflects current scientific knowledge, policies, or practices. 
TERMS-Prices F. O. B. Petoskey, Mich., subject to prior sale and change without notice. All bulbs commercially pure, up to size and of first quality. No charge for packing. 25 bulbs at 100 rate if priced per 100. 100 at 1,000 rate. 5\% discount for cash. 25\% deposit required if bulbs are to be held for spring shipment.

\begin{tabular}{|c|c|c|c|}
\hline $\begin{array}{l}\text { Variety } \\
\text { Alice Tiplady }\end{array}$ & Per & $\begin{array}{l}\text { No. } 1 \\
1 / 2 \text { in. up } \\
\text { gq.5. }\end{array}$ & $\begin{array}{l}\text { No. } \\
11 / 4,-11 / 2 \\
\$ 20.00\end{array}$ \\
\hline America & $\stackrel{1,00}{ }$ & 12.00 & 10.00 \\
\hline Autumn Queen & $"$ & 15.00 & 12.00 \\
\hline Arizona Rose & $"$ & 30.00 & 24.00 \\
\hline Evelyn Kirtland & " & 30.00 & 24.00 \\
\hline Flora _ & " & 40.00 & 32.00 \\
\hline Gaiety -- & " & 30.00 & 24.00 \\
\hline Gretchen Zang & $"$ & 22.00 & 18.00 \\
\hline Jean Dieulafoy & $"$ & 20.00 & 16.00 \\
\hline Le Marechal Foch & ", & & 10.00 \\
\hline Maiden's Blush & " & 20.00 & 16.00 \\
\hline Miss Helon Erentwin & " & 20.00 & 16.00 \\
\hline Mrs. Frank Pendleton & " & & 15.00 \\
\hline Panama & $"$ & 12.00 & 10.00 \\
\hline Peace & " & 15.00 & 12.00 \\
\hline Prince of Wales & $"$ & 20.00 & 20.00 \\
\hline Primuliaus Hybrids & " & 10.00 & 8.00 \\
\hline Rose 1910 & " & 2000 & 16.00 \\
\hline War & $"$ & 35.00 & 28.00 \\
\hline Wilbrink & $"$ & 15.00 & 12.00 \\
\hline Fancy Mixed-all colors & " & 1,000 & 8.00 \\
\hline Anna Eberius & 100 & 3.00 & 2.50 \\
\hline Baron Hulot & $"$ & 4.00 & 3.50 \\
\hline Blue Jay & $"$ & 4.00 & 3.50 \\
\hline Best Violet & $"$ & 4.00 & 3.50 \\
\hline Crimson Glow & $"$ & 3.00 & 2.50 \\
\hline E. J. Shaylor & $"$ & 3.00 & 2.50 \\
\hline Elizabeth Tabor & $"$ & 12.00 & 10.00 \\
\hline Golden Gate (Prim) & $"$ & 3.00 & 2.50 \\
\hline Golden Glow & " & 4.00 & 3.50 \\
\hline Herada & " & 3.00 & 2.50 \\
\hline Halley _- _. & $"$ & 2.00 & 1.50 \\
\hline Jewell & $"$ & 5.00 & 4.00 \\
\hline Lily White - & $"$ & 3.00 & 2.50 \\
\hline Large Buff & $"$ & 6.00 & 5.00 \\
\hline Loveliness _. _ & $"$ & 5.00 & 4.00 \\
\hline Louise & $"$ & 3.50 & 2.75 \\
\hline Mrs. Geo. W. Moulton & $"$ & 3.00 & 2.50 \\
\hline Mr. Mark & ", & 4.00 & 3.25 \\
\hline Mona Lisa & " & 4.00 & 3.50 \\
\hline Odin & $"$ & 4.00 & 3.50 \\
\hline Pink Wonder & $"$ & 6.00 & 5.00 \\
\hline Purity-large late white & $"$ & 4.00 & 3.50 \\
\hline Pink Perfection & " & 5.00 & 4.00 \\
\hline Purple Glory & " & 10.00 & 8.00 \\
\hline Red Canna & $"$ & 4.00 & 3.50 \\
\hline Rose Ash & $"$ & 3.50 & 3.00 \\
\hline Schwaben -- & $"$ & 2.00 & 1.50 \\
\hline Twilight & " & 8.00 & 4.00 \\
\hline Twilight _. ... & $"$ & 8.00 & 6.00 \\
\hline & $"$ & 4.00 & 3.50 \\
\hline \multirow[t]{2}{*}{ Yellow Hammer } & $"$ & 4.00 & 4.00 \\
\hline & & liolus & \\
\hline
\end{tabular}

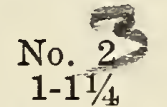

$\$ 15.00$

8.00

9.00

20.00

20.00

26.00

20.00

15.00

12.00

8.00

12.00

12.00

12.00

8.00

10.00

16.00

6.00

12.00

23.00

10.00

6.00

No. 4

$3 / 4,-1$

$\$ 12.00$

6.00

7.00

16.00

16.00

24.00

18.00

12.00

10.00

6.00

10.00

10.00

10.00

6.00

8.00

12.00

4.00

10.00

19.00

8.00

4.00

2.50

3.50

3.50

2.50

10.00

3.50

2.50

4.00

2.50

4.00

2.75

3.25

3.50

3.50

3.50

4.00

3.50

3.00

4.00

6.00

4.00

\section{Gladiolus Petoskey}

Originated by the late C. M. Grossman.

Description-Dark rose red tinted carmen, lemon yellow throat blotched maroon. Tall well formed spike with wide open large sized flowers. Makes fine large bulblets that germinate. Average rating by Gersdorff, 92. An excellent variety for late cut flowers.

Prices per $100-$ No. $1, \$ 8.00$; No. $2, \$ 6.00$. 
